\title{
Las complicaciones de la cirugía radical de próstata en cáncer localizado dependen de la edad
}

Urinary and Sexual Function After Radical Prostatectomy for Clinically Localized Prostate. The Prostate Cancer Outcome Study. Stanford J, Feng Z, Hamilton A, et al. JAMA 2000; 283: 354-360

\section{Objetivo}

Evaluar los cambios en la micción y la sexualidad en hombres sometidos a prostatectomía radical por cáncer de próstata localizado.

\section{Lugar}

Registros poblacionales de cáncer en seis regiones de EEUU

\section{Diseño}

Cohorte poblacional con 24 meses de seguimiento.

\section{Participantes}

Se evaluaron 1291 hombres entre 39 y 79 años con diagnóstico de cáncer de próstata sometidos a prostatectomía radical por enfermedad clínicamente localizada, dentro de los seis mesés del diagnóstico.

\section{Medición de resultados}

Distribución y cambios en los hábitos miccionales y la función sexual, reportado por los pacientes en forma basal, a los 6,12 , y 24 meses después del diagnóstico.

\section{Resultados}

Luego de 18 meses de la prostatectomía radical, $8.4 \%$ de los hombres reportaban incontinencia urinaria y $59.9 \%$ impotencia sexual.

Entre los hombres sin disfunción eréctil antes de la cirugía, la impotencia como complicación varió en función del procedimiento: sin conservación de la inervación $65.5 \%$, con conservación unilateral $58.6 \%$ y con conservación bilateral 56\%. Luego de 18 meses $41.9 \%$ reportó que la sexualidad era un problema moderado a grave.

Tanto las alteraciones de la micción como de la función sexual aumentaban con la edad. A los 18 meses, $39 \%$ de los pacientes menores de 60 años reportaba no tener problemas sexuales contra $15.3 \%-21.7 \%$ de los mayores ( $<<0,001$ ); y $13.8 \%$ de los hombres entre 75-79 años reportaban incontinencia urinaria contra $0.7-3.6 \%$ en los más jóvenes $(p<0,001)$.

\section{Conclusión}

La prostatectomía radical se asocia en forma significativa con disfunción sexual eréctil y en menor medida con alteraciones miccionales.

\section{Comentario}

Los hombres tenemos dos mecanismos de continencia urinaria uno distal, el esfinter externo y el otro proximal, el cuello vesical. Durante la PR (prostatectomía radical) este último se ve afectado por la resección de la próstata y la continencia urinaria dependerá del esfinter externo. La incontinencia urinaria es sin duda uno de los grandes problemas de la PR. Los autores reportan el $8,4 \%$ de incontinentes luego de 18 meses de seguimiento encontrando que el grado de incontinencia está relacionado con la edad del paciente. La edad es un predictor del estado de la función esfinteriana, dato confirmado al relacionar los incontinentes jóvenes (10\%) vs. los añosos $(40 \%)$. Además la población de pacientes menor de 65 años recuperó más rápidamente el control esfinteriano que los de más de 65 años.

La PR es un tratamiento que debe indicarse a quienes terigan una expectativa de vida de más de 10 años, realizándose a menores de 70, evitando de este modo los altos porcentajes de incontinentes en las personas mayores. Luego de esa edad e cáncer de próstata ha demostrado ser, en general, una enfermedad menos agresiva y que puede manejarse de manera más conservadora.
En nuestro Servicio hemos comprobado que la rehabilitación perineal temprana, nos permite una más rápida recuperación de la continencia urinaria.

La función sexual es el otro gran problema de la PR. Los autores señalan que el $60 \%$ de los pacientes refieren falta de erecciones satisfactorias. Si bien conocemos el sitio anatómico donde se encuentran los paquetes neurovasculares que proporcionan la erección, aún aquellos en los que la preservación es uni o bilateral los porcentajes de impotencia oscilan entre el $59 \%$ y $56 \%$ respectivamente.

Nuevamente se observa que la edad ( $<$ de 60 años) es un factor decisivo al momento de evaluar el tiempo de recuperación de la potencia y el número de impotentes definitivo.

A pesar de las complicaciones mencionadas el estudio reporta que el $75,5 \%$ está satisfecho con el tratamiento recibido y el $71,5 \%$ volvería a optar por él.

La PR es una excelente manera de controlar el cáncer de próstata, y los porcentajes de complicaciones son mejorados al seleccionar adecuadamente los casos. La edad es un criterio de selección que además nos permite tratar la población con cánceres más agresivos. 